\title{
Family History of Diabetes Mellitus Determines Insulin Sensitivity and $B$ Cell Function in Polycystic Ovary Syndrome
}

\author{
J. VRBÍKOVÁ, T. GRIMMICHOVÁ, K. DVOŘÁKOVÁ, M. HILL, S. STANICKÁ, \\ K. VONDRA
}

Institute of Endocrinology, Prague, Czech Republic

Received April 27, 2007

Accepted June 7, 2007

On-line July 26, 2007

\begin{abstract}
Summary
Objective: To examine the impact of family history of diabetes mellitus 2 (DM 2) on insulin sensitivity and secretion in lean women with polycystic ovary syndrome (PCOS). Thirteen healthy women (C), 14 PCOS without family history of DM 2 (FH-) and 8 PCOS with family history of DM $2(\mathrm{FH}+)$ were examined using euglycemic hyperinsulinemic clamp and an arginine secretion test (insulin and glucagon at fasting glycemia ( $\mathrm{AIR}_{\mathrm{FG}}$ and $A G \mathrm{R}_{\mathrm{FG}}$ ) and at hyperglycemia $\left(\mathrm{AIR}_{14}\right.$ and $\left.\mathrm{AGR}_{14}\right)$ ). $\mathrm{FH}+$ women were more insulin resistant than $\mathrm{FH}$ - with lower insulin sensitivity index corrected per lean body mass $(p<0.05)$. They had significantly higher triglycerides $(p<0.05)$ and lower HDL-cholesterol $(p<0.05)$ than $\mathrm{C}$ or $\mathrm{FH}-$ women. Concerning insulin secretion, $\mathrm{AIR}_{\mathrm{FG}}$ was increased in $\mathrm{FH}+$ women comparing $\mathrm{FH}-$ women $(\mathrm{p}<0.05)$. Disposition indices derived from $\mathrm{AIR}_{\mathrm{FG}}$ or $\mathrm{AIR}_{14}$ and insulin sensitivity index did not differ between $\mathrm{FH}+$ or FH-. Thus, women with PCOS with the concomitant family history of DM 2 have lower insulin sensitivity than healthy control women. Insulin resistance observed in these women with PCOS is compensated by increased insulin secretion.
\end{abstract}

\section{Key words}

Polycystic ovary syndrome • Insulin resistance • Insulin secretion - Diabetes mellitus

\section{Corresponding author}

J. Vrbíková, Institute of Endocrinology, Národní 8, 11694 Prague 1, Czech Republic. Fax +420-2-24905325. E-mail: jvrbikova@endo.cz

\section{Introduction}

Polycystic ovary syndrome (PCOS) is considered as a risk factor for diabetes mellitus type 2 (DM 2). However, only a fraction of PCOS-affected women will eventually develop diabetes (Legro et al. 2004). It is possible to suppose that only a subgroup of PCOS-affected women is at a special risk for DM 2. Risk factors of DM 2 include family history of DM 2, obesity, insulin resistance and defects in insulin secretion.

Family history of DM 2 occurred with a significantly greater frequency in women with PCOS with impaired glucose tolerance (IGT) or with DM 2 than in those with normal glucose tolerance (Ehrmann et al. 2005). Insulin resistance is supposed to affect a significant proportion of women with PCOS (Legro et al. 2004), but not all women with PCOS are insulin-resistant. We have previously shown using euglycemic clamp that only obese, but not lean women with PCOS were more insulin-resistant than lean controls (Vrbíková et al. 2004). These results agree with other studies (Holte et al. 1994, Ovesen et al. 1993). However, some investigators have found insulin resistance in both lean and obese women with PCOS (Dunaif et al. 1989, 1992, Toprak et al. 2001). The cited studies were not controlled exactly for the factors known to influence the degree of insulin resistance, such as the family history of DM 2.

B-cell dysfunction is another risk factor contributing to the development of DM 2. It is important to examine simultaneously insulin sensitivity and secretion by independent methods, as these variables are interrelated. Insulin secretion increases with decreasing insulin sensitivity, and vice versa, to maintain normal 
glucose tolerance (Kahn et al. 1993). Discrepant results concerning insulin secretion in women with PCOS were also published. B-cell dysfunction inherent to PCOS and independent of obesity and family history of DM 2 was described using ivGTT in women with PCOS (Dunaif and Finegood 1996). On the other hand, an increased insulin secretion normalized for insulin sensitivity over the entire range of BMI was found, when women with PCOS were examined by ivGTT and euglycemic clamp (Holte et al. 1994). Ehrmann et al. (1995) used ivGTT, oscillatory and graded i.v. glucose infusion to assess insulin secretion in obese women with PCOS and found B-cell dysfunction only in women with family history of DM 2.

We hypothesized that women affected with PCOS with a first degree relative suffering from DM 2 could have more profound defects in insulin sensitivity and B-cell function than those without family history of DM 2. We decided to use arginine secretion test to evaluate simultaneously different aspects of $\beta$ - and $\alpha$-cell function. Euglycemic clamp was used as an independent measurement of insulin sensitivity. Arginine secretion test has the advantage of using isoglycemic condition in all subjects and was thoroughly validated for the measurement of insulin secretion (Larsson and Ahren 1998).

\section{Subjects and Methods}

Women with PCOS $(\mathrm{n}=22)$ diagnosed according to NIH criteria (Dunaif 1997), were enrolled in the study in an outpatient tertiary endocrine care department. Eight of them had family history of DM 2 among their first degree relatives $(\mathrm{FH}+)$. The rest of the group $(\mathrm{n}=14)$ was free of family history of DM 2 (FH-). All women had a clinical manifestation of hyperandrogenemia presented as hirsutism and/or acne and an elevation of the free testosterone index $>6$ and/or androstenedione above the upper limit of the normal range. All of the women were in good health without any other serious disorder. Women with epilepsy or migraines were excluded. In all patients $17-\mathrm{OH}$ progesterone levels were determined in the early follicular phase of their cycle, and if levels were between $5-10 \mathrm{nmol} / \mathrm{l}$, an ACTH test was used to exclude late-onset congenital adrenal hyperplasia. Hyperprolactinemia (prolactin levels), hypercortisolism (plasma cortisol, and if necessary, 24-h urinary cortisol excretion or short dexamethasone suppression test with $1 \mathrm{mg}$ of dexamethasone at 22-23 p.m.), thyroid dysfunction (TSH, fT4, anti-thyreoglobulin and anti-thyroid-peroxidase antibodies) were excluded. The control group was composed of healthy women $(n=13)$ who were free of any clinical signs of hyperandrogenism and showed regular menstrual cycles (28-33 days). They also had not used oral contraceptives for at least the preceding 3 months. They were recruited from the health care personnel and from subjects seeking endocrine evaluation, after excluding any endocrine pathology.

The local ethical committee of the Institute of Endocrinology approved the protocol of the study.

The patients and controls were evaluated at the clinical department as outpatients, and after signing a written informed consent they underwent clinical examination, and blood sampling for hormonal and biochemical examinations between days 3 and 6 of the menstrual cycle or, in the case of secondary amenorrhoea, at any time. Weight and height was measured and lean body mass was calculated according to the equation of Hume (1966). Two blood pressure readings were obtained from seated patients after a 10-min rest; the mean value was used for further analysis. After basal blood samples were taken, oral glucose tolerance test (oGTT) with sampling for blood glucose, insulin and C peptide in the $0^{\text {th }}, 30^{\text {th }}, 60^{\text {th }}$ and $120^{\text {th }}$ minutes was carried out with 75 grams of oral glucose load. Samples were centrifuged and plasma was frozen at $-20{ }^{\circ} \mathrm{C}$ until analysis. Glucose tolerance was evaluated according to revised WHO criteria (1997). In controls and FH-, normal glucose tolerance was found, in one subject with $\mathrm{FH}+$, impaired glucose tolerance was found.

Euglycemic hyperinsulinemic $\left(1 \mathrm{mIU} \cdot \mathrm{kg}^{-1} \cdot \mathrm{min}^{-1}\right)$ clamp was performed as described previously (DeFronzo et al. 1979). Insulin sensitivity was determined from the values obtained during the steady-state period, between $100^{\text {th }}-120^{\text {th }}$ minutes. Target blood glucose level was 5.0 $\mathrm{mmol} / \mathrm{l}$, with the coefficient of variance less than $5 \%$. Following parameters were calculated based on clamp results: glucose disposal rate $(\mathrm{M})$ was defined as the amount of glucose supplied by the infusion to maintain the desired blood glucose level $\left(\mathrm{M}, \mu \mathrm{mol} \cdot \mathrm{kg}^{-1} \cdot \mathrm{min}^{-1}\right)$, and the insulin sensitivity index (ISI, $\mu$ mol. $\mathrm{kg}^{-1} \cdot \mathrm{min}^{-1}$ per mIU. $l^{-1} \times 100$ ) was defined as the ratio of glucose disposal rate and the average insulin concentration during the observed period corrected either for kilogram of body weight (ISI) or per kilogram of lean body mass (ISI-LBM).

To evaluate $\alpha$ - and $\beta$-cell secretion, an arginine test was performed as described by Larsson et al. (1998). Briefly, intravenous cannulae were placed in antecubital 
veins on both arms (one for glucose infusion and the second for sampling). Baseline samples for insulin and glucagon were taken at $-5^{\text {th }}$ and $-2^{\text {nd }}$ minutes. Subsequently, $5 \mathrm{~g}$ of arginine (diluted in $40 \mathrm{ml}$ of physiological solution) was applied at time 0 during $50 \mathrm{~s}$ as an intravenous bolus and samples for insulin and glucagon were taken again at the $2^{\text {nd }}, 3^{\text {rd }}, 4^{\text {th }}$ and $5^{\text {th }}$ minute. After that, a variable-rate infusion of $15 \%$ glucose solution was started in order to raise and maintain blood glucose levels between $13-15 \mathrm{mmol} / \mathrm{l}$ and finally, new baseline samples were taken; arginine bolus was repeated and new samples for insulin and glucagon were taken at the $2^{\text {nd }}, 3^{\text {rd }}, 4^{\text {th }}$ and $5^{\text {th }}$ minute thereafter.

Blood glucose was determined in the whole blood by electrochemical method (Super GL, Dr. Müller Geräte Bau, GmbH, Freital Germany). C peptide was estimated by IRMA (Immunotech, Prague, Czech Republic), with an intra- and inter-assay CV of $4.1 \%$ and $5.1 \%$, respectively. Insulin was estimated by IRMA (Immunotech, Prague, Czech Republic) with an intraand inter-assay $\mathrm{CV}$ of $4.6 \%$ and $5.3 \%$, respectively. Total cholesterol, HDL cholesterol and triglycerides were assessed by photometry (Ecoline 25, Merck Vitalab Eclipse, Darmstadt, Germany), with intra-assay CVs $1.6 \%, 1.7 \%$ and $1.2 \%$ and inter-assay CVs of 1.9 $\%, 2.1 \%$ and $1.9 \%$, respectively. Testosterone (T) was determined by RIA with the use of own antiserum (antitestosterone-3-carboxymethyloxid BSA), with intraassay and inter-assay CVs of $10.2 \%$ and $10 \%$, respectively. Androstenedione (A) was estimated by RIA with the use of own antiserum (antiandrostendione-6-carboxymethyl-oxide BSA), with intra-assay and inter-assay CVs of $10 \%$, and $10.2 \%$ respectively. Dehydroepiandrosterone (DHEA) was estimated after extraction with dichloromethane by RIA (Immunotech, Marseille, France), with an intra-assay $\mathrm{CV}$ of $6 \%$ and inter-assay $\mathrm{CV}$ of $12.1 \%$. Dehydroepiandrosterone sulfate (DHEA-S) was estimated by RIA (Immunotech, Marseille, France), with an intra-assay $\mathrm{CV}$ of $3.5 \%$ and inter-assay $\mathrm{CV}$ of $10.2 \% .17-\mathrm{OH}$ progesterone (17 OHP) was determined after diethylether extraction with RIA (Immunotech, Prague, Czech Republic), with an intra-assay CV of 5.2 $\%$, and inter-assay $\mathrm{CV}$ of $6.5 \%$. Estradiol was determined with RIA (Immunotech, Prague, Czech Republic) with an intra-assay CV of $4.4 \%$ and an interassay $\mathrm{CV}$ of $4.6 \%$. Luteinizing hormone ( $\mathrm{LH}$ ) was determined by IRMA (Immunotech, Prague, Czech Republic) with an intra-assay CV of $3.7 \%$ and an inter- assay $\mathrm{CV}$ of $4.3 \%$. Follicle-stimulating hormone (FSH) was determined by IRMA (Immunotech, Prague, Czech Republic) with an intra-assay CV of $2.6 \%$, and an interassay CV of $4.5 \%$. Sex-hormone binding globulin (SHBG) was determined by IRMA (Orion, Espoo, Finland) with an intra-assay CV of $6.1 \%$, and an interassay $\mathrm{CV}$ of $7.9 \%$.

\section{Computations and statistics}

The homeostatic model assessment of insulin resistance (HOMA-IR) was calculated as: fasting insulin (mIU/l) x fasting glucose $(\mathrm{mmol} / \mathrm{l}) / 22.5$ (Matthews et al . 1985).

The acute insulin response (AIR) to arginine was calculated as the mean of +2 to +5 min samples minus the pre-stimulus insulin concentration for the fasting values $\left(\mathrm{AIR}_{\mathrm{FG}}\right)$ and glucose-potentiated values $\left(\mathrm{AIR}_{14}\right)$. The slope between AIR at fasting blood glucose and at blood glucose $14 \mathrm{mmol} / 1$ slope $_{\mathrm{AIR}}=$ $\Delta \mathrm{AIR} / \Delta$ glucose) was calculated as a measure of the glucose potentiation of $\beta$-cell secretion since it is known that augmentation of the insulin response to arginine is linearly related to the glucose level at levels below 17 $\mathrm{mmol} / \mathrm{l}$. The acute glucagon response $\left(\mathrm{AGR}_{\mathrm{FG}}, \mathrm{AGR}_{14}\right)$ and the slope $\mathrm{AGR}_{\mathrm{AR}}$ were calculated in the same manner. Disposition indices (Di) were calculated according to Kahn et al. (1993) using the values of ISI and AIR $_{\mathrm{FG}}$ $\left(\mathrm{Di}_{\mathrm{FG}}\right), \mathrm{AIR}_{14}\left(\mathrm{Di}_{\mathrm{G}}\right)$ or slope $_{\mathrm{AIR}}\left(\mathrm{Di}_{\mathrm{S}}\right)$. Kruskal-Wallis one-way ANOVA was done. The individual differences between the subgroups were evaluated by KruskalWallis robust multiple-comparison $\mathrm{z}$-value test. $\mathrm{P}<0.05$ values were considered as significant. NCSS 2001 (Number Cruncher Statistical Systems, Kaysville, Utah, USA) was used for the calculations.

\section{Results}

Anthropometric and biochemical parameters are given in Table 1. Body mass index, lean body mass, systolic and diastolic blood pressure did not differ between groups. $\mathrm{FH}+$ women have significantly higher triglycerides (ANOVA $\mathrm{p}<0.05$ ) and lower HDL-cholesterol (ANOVA $\mathrm{p}<0.05)$ than $\mathrm{C}$ or $\mathrm{FH}-$ women. Concerning hormonal profile, higher testosterone and higher $\mathrm{LH}$ was present in both $\mathrm{FH}+$ and $\mathrm{FH}-$ women (ANOVA $\mathrm{p}<0.002$ and $\mathrm{p}<0.02$; respectively) in comparison with the control group. $\mathrm{FH}^{+}$ women have lower values of DHEAS than $\mathrm{FH}-$ or than $\mathrm{C}$ (ANOVA $p<0.0001$ ).

Results from arginine secretion tests and 
Table 1. Anthropometrical, biochemical and hormonal characteristics of women with polycystic ovary syndrome (PCOS) with (FH+) or without (FH-) family history of type 2 diabetes mellitus comparing healthy controls.

\begin{tabular}{|c|c|c|c|c|c|c|c|c|}
\hline & \multicolumn{2}{|c|}{$\begin{array}{c}\text { PCOS FH- } \\
(n=14)\end{array}$} & \multicolumn{2}{|c|}{$\begin{array}{c}\text { PCOS FH+ } \\
(n=8)\end{array}$} & \multicolumn{2}{|c|}{$\begin{array}{c}\text { Controls } \\
(n=13)\end{array}$} & \multirow[t]{2}{*}{$\begin{array}{c}\text { ANOVA } \\
\mathbf{p}<\end{array}$} & \multirow{2}{*}{$\begin{array}{l}\text { Significant between } \\
\text { group differences } \\
(\mathbf{p}<\mathbf{0 . 0 5})\end{array}$} \\
\hline & mean & SD & mean & SD & mean & SD & & \\
\hline Age (years) & 24.2 & 4.8 & 27.5 & 3.2 & 28.7 & 5.6 & & \\
\hline Body mass index $\left(\mathrm{kg} / \mathrm{m}^{2}\right)$ & 22.52 & 2.80 & 23.54 & 6.04 & 21.82 & 2.24 & & \\
\hline Lean body mass (kg) & 43.66 & 5.11 & 46.37 & 4.20 & 45.58 & 2.78 & & \\
\hline Systolic BP (mm Hg) & 112 & 8.9 & 121 & 13.5 & 114 & 7.8 & & \\
\hline Diastolic BP (mm Hg) & 71 & 7.5 & 75 & 8.2 & 74 & 7.9 & & \\
\hline Cholesterol (mmol/l) & 4.24 & 0.51 & 4.26 & 1.21 & 4.13 & 0.66 & & \\
\hline HDL-cholesterol (mmol/l) & 1.32 & 0.28 & 1.33 & 0.43 & 1.78 & 0.31 & 0.05 & $\mathrm{FH}+$ vs $\mathrm{C}, \mathrm{FH}-$ vs $\mathrm{C}$ \\
\hline Triglycerides (mmol/l) & 0.66 & 0.18 & 0.82 & 0.24 & 0.71 & 0.27 & 0.05 & $\mathrm{FH}+$ vs FH- \\
\hline Testosterone (nmol/l) & 2.75 & 0.80 & 2.82 & 1.12 & 1.74 & 0.46 & 0.002 & $\mathrm{FH}+$ vs $\mathrm{C}, \mathrm{FH}-$ vs C \\
\hline Estradiol (nmol/l) & 0.23 & 0.14 & 0.18 & 0.08 & 0.18 & 0.11 & & \\
\hline 17 OH progesterone $(\mathrm{nmol} / \mathrm{l})$ & 1.99 & 0.96 & 1.71 & 0.78 & 1.78 & 0.87 & & \\
\hline DHEAS $($ Hmol/l) & 7.73 & 2.21 & 5.23 & 2.70 & 4.00 & 2.07 & 0.0001 & $\mathrm{FH}+$ vs $\mathrm{FH}-, \mathrm{FH}+$ vs $\mathrm{C}$ \\
\hline DHEA (nmol/l) & 30.92 & 11.00 & 25.45 & 10.30 & 18.31 & 9.58 & 0.03 & $\mathrm{FH}-$ vs C \\
\hline Androstenedione (nmol/l) & 5.76 & 2.21 & 8.24 & 4.64 & 6.05 & 1.73 & & \\
\hline$L H(m I U / l)$ & 5.61 & 2.83 & 7.59 & 4.25 & 3.16 & 1.69 & 0.02 & $\mathrm{FH}+$ vs $\mathrm{C}, \mathrm{FH}-$ vs $\mathrm{C}$ \\
\hline FSH (mIU/l) & 4.81 & 2.02 & 4.73 & 1.68 & 4.95 & 2.57 & & \\
\hline SHBG $(\mathrm{nmol} / \mathrm{l})$ & 45.72 & 20.01 & 48.34 & 17.97 & 65.84 & 42.28 & & \\
\hline
\end{tabular}

DHEAS - dehydroepiandrosterone sulfate; DHEA - dehydroepiandrosterone; FSH - follicle-stimulating hormone; LH - luteinizing hormone, SHBG - sex hormone binding globulin; BP - blood pressure.

euglycemic clamps are shown in Table 2. Fasting blood glucose did not differ between women with PCOS or controls. Fasting insulin was higher in both $\mathrm{FH}+$ and $\mathrm{FH}-$ women than in $\mathrm{C}$ (ANOVA $\mathrm{p}<0.04)$. $\mathrm{FH}-$ women have higher basal glucagon (ANOVA $\mathrm{p}<0.02$ ) than $\mathrm{C}$ and the similar trend for $\mathrm{FH}+$ was observed. HOMA-IR was higher in $\mathrm{FH}+$ women only than in $\mathrm{C}$ (ANOVA $\mathrm{p}<0.05$ ). Similarly, insulin sensitivity index from euglycemic clamp corrected per LBM was lower in $\mathrm{FH}+$ women than in $\mathrm{C}$ with no difference between $\mathrm{FH}_{-}$ women and $\mathrm{C}$ (ANOVA $\mathrm{p}<0.05)$. During arginine secretion test, a similar degree of hyperglycemia was achieved in all subgroups. Concerning insulin secretion, $\mathrm{AIR}_{\mathrm{FG}}$ was higher in $\mathrm{FH}+$ women comparing $\mathrm{FH}$ women (ANOVA $\mathrm{p}<0.05$ ). $\mathrm{AIR}_{14}$ and slope $\mathrm{AIR}_{\mathrm{A}}$ did not differ significantly. Glucagon secretion during the arginine tests did not differ between women with PCOS and $\mathrm{C}$.

Disposition indices derived from $\mathrm{AIR}_{\mathrm{FG}}, \mathrm{AIR}_{14}$ or slope ${ }_{A I R}$ and ISI did not differ between women with PCOS and C.

\section{Discussion}

The present study describes decreased insulin sensitivity only in women with PCOS and family history of DM 2. This finding is in accordance with the observations of insulin resistance as an early defect in the development of DM 2 (Ferrannini 1998). The second main finding is the preserved insulin secretory compensation in these women.

Women with PCOS and family history of DM 2 had significantly higher triglycerides with no difference in total cholesterol compared to their counterparts without family history of DM 2 or healthy subjects. Ehrmann et al. (2005) studied obese women with PCOS according to family history of DM 2 and found significantly higher waist circumference, hemoglobin $\mathrm{A} 1 \mathrm{C}$, fasting insulin and glucose in women with a positive family history of diabetes. However, the lipid levels were not evaluated in their study.

We observed an increased insulin secretion after arginine bolus at fasting blood glucose levels $\left(\mathrm{AIR}_{\mathrm{FG}}\right)$ in 
Table 2. Insulin sensitivity and $\beta$ - and $\alpha$-cell secretion in women with polycystic ovary syndrome (PCOS) with (FH+) or without (FH-) family history of type 2 diabetes mellitus comparing healthy controls.

\begin{tabular}{|c|c|c|c|c|c|c|c|c|}
\hline & \multicolumn{2}{|c|}{$\begin{array}{c}\text { PCOS FH- } \\
(n=14)\end{array}$} & \multicolumn{2}{|c|}{$\begin{array}{c}\text { PCOS FH+ } \\
(\mathbf{n}=8)\end{array}$} & \multicolumn{2}{|c|}{$\begin{array}{c}\text { Controls } \\
(\mathrm{n}=13)\end{array}$} & \multirow[t]{2}{*}{$\begin{array}{c}\text { ANOVA } \\
\mathbf{p}<\end{array}$} & \multirow{2}{*}{$\begin{array}{c}\text { Group } \\
\text { differences } \\
(\mathbf{p}<0.05)\end{array}$} \\
\hline & mean & SD & mean & SD & mean & SD & & \\
\hline $\begin{array}{l}\text { Fasting blood } \\
\text { glucose }(\mathrm{mmol} / \mathrm{l})\end{array}$ & 4.66 & 0.30 & 4.89 & 0.40 & 4.73 & 0.44 & & \\
\hline $\begin{array}{l}\text { Blood glucose during } \\
\text { arginine test } \\
\text { (mmol/l) }\end{array}$ & 14.29 & 1.04 & 14.47 & 0.92 & 13.86 & 0.94 & & \\
\hline Glucagon (pmol/l) & 38.69 & 13.21 & 35.51 & 10.48 & 27.2 & 8.49 & 0.02 & $\mathrm{FH}-$ vs C \\
\hline$A G R_{F G}(\mathrm{pmol} / \mathrm{l})$ & 45.26 & 29.05 & 55.78 & 38.23 & 43.47 & 27.04 & & \\
\hline$A G R_{14}(\mathrm{pmol} / \mathrm{l})$ & 24.81 & 11.89 & 29.63 & 19.49 & 17.27 & 10.48 & & \\
\hline Suppressibility of $G$ & 23.44 & 17.90 & 26.15 & 24.93 & 26.20 & 20.50 & & \\
\hline $\begin{array}{l}\text { Slope }_{A G R} \\
(\mathrm{pmol} / \mathrm{mmol})\end{array}$ & -2.18 & 2.25 & -2.83 & 3.03 & -2.99 & 2.53 & & \\
\hline Insulin (mIU/l) & 6.06 & 2.62 & 6.43 & 3.64 & 4.20 & 1.62 & 0.04 & $\begin{array}{l}\mathrm{FH}-\text { vs } \mathrm{C} \\
\mathrm{FH}+\text { vs } \mathrm{C}\end{array}$ \\
\hline$A I R_{F G}(m I U / l)$ & 20.68 & 8.76 & 32.71 & 7.18 & 29.27 & 21.84 & 0.05 & $\mathrm{FH}+\mathrm{vs} \mathrm{FH}-$ \\
\hline $\operatorname{AIR}_{14}(\mathrm{mIU} / \mathrm{l})$ & 132.68 & 65.63 & 131.78 & 22.56 & 161.67 & 128.60 & & \\
\hline Slope $_{\text {AIR }}(\mathrm{mIU} / \mathrm{mmol})$ & 84.73 & 49.54 & 74.65 & 12.60 & 110.57 & 99.02 & & \\
\hline$H O M A-I R$ & 1.29 & 0.65 & 1.59 & 0.61 & 0.91 & 0.33 & 0.05 & $\mathrm{FH}+$ vs $\mathrm{C}$ \\
\hline $\begin{array}{l}\text { Insulin during clamp } \\
(m I U / l)\end{array}$ & 67.13 & 34.01 & 62.10 & 6.70 & 60.53 & 13.71 & & \\
\hline $\begin{array}{l}\text { Insulin sensitivity } \\
\text { index (ISI) }\end{array}$ & 71.98 & 23.94 & 51.50 & 28.53 & 76.03 & 22.13 & 0.07 & $\mathrm{FH}+$ vs $\mathrm{C}$ \\
\hline $\begin{array}{l}\text { Insulin sensitivity } \\
\text { index (ISI-LBM) } \\
\text { Disposition Indices }\end{array}$ & 99.83 & 33.28 & 73.04 & 39.00 & 102.51 & 28.50 & 0.05 & $\begin{array}{l}\mathrm{FH}+\text { vs } \mathrm{FH}- \\
\mathrm{FH}+\text { vs } \mathrm{C}\end{array}$ \\
\hline$I S I^{*} A I R_{F G}$ & 1446.10 & 693.20 & 1657.62 & 950.69 & 1994.74 & 1151.02 & & \\
\hline$I S I *$ Slope $_{A I R}$ & 5529.16 & 2642.44 & 3955.40 & 2649.03 & 7660.68 & 5905.03 & 0.14 & $\mathrm{FH}+$ vs C \\
\hline$I S I^{*} A I R_{14}$ & 8797.46 & 3595.58 & 6755.30 & 3933.23 & 11215.83 & 7225.44 & & \\
\hline
\end{tabular}

$A I R_{F G}$ - the acute insulin response to arginine for the fasting values; $A \mathrm{AR}_{14}$ - the acute insulin response to arginine for glucosepotentiated values; G - glucagon; $A_{G R}$ - the acute glucagon response to arginine for the fasting values; AGR ${ }_{14}$ - the acute glucagon response to arginine for glucose-potentiated values; HOMA-IR - homeostatic model assessment of insulin resistance; ISI - insulin sensitivity index; LBM - lean body mass; Slope ${ }_{\text {AIR }}$ - measure of the glucose potentiation of B-cell secretion ; Slope $_{A G R}$ - measure of the glucose suppression of $\alpha$-cell secretion.

women with PCOS and family history of DM 2, compared to women with PCOS but without family history of DM 2. Previous studies conducted in women with PCOS used ivGTT to examine insulin secretion. These studies have found either $\beta$-cell dysfunction inherent to PCOS and independent of obesity and family history of DM 2 (Dunaif and Finegood 1996), or B-cell dysfunction in women with family history of DM 2 only (Ehrmann et al. 1995). Finally, Holte et al. (1994) described an increased insulin secretion over the entire range of BMI. It is possible to encounter subjects with glucose intolerance and acute insulin response in normal range, while other subjects with the same degree of glucose intolerance completely lack this response. On the other hand, when subjects become diabetic, the first phase of insulin secretion is lost (Pratley and Weyer 2001). This heterogeneity could partly explain the observed discrepancies between the above cited studies. 
Another explanation for the discrepant results could be the fact that during ivGTT, the subjects achieved different levels of blood glucose and insulin secretion was not examined under isoglycemic condition. We used arginine secretion testing which makes possible to achieve the same degree of hyperglycemia in all subjects. We observed increased acute insulin response to arginine in women with PCOS with family history of DM 2. The slope $_{\mathrm{AIR}}$ and insulin response at hyperglycemia was not different between women with PCOS and controls. The AIR $_{\mathrm{FG}}$ quantifies the direct acute $\beta$-cell response to a sudden arginine challenge and is therefore related to the rapid efficiency of the exocytotic machinery of the $\beta$-cell. We did not measure maximal secretory capacity of $\beta$-cell as this could be achieved when blood glucose is equal or higher than $25 \mathrm{mmol} / \mathrm{l}$. Ahren and Larsson (2002) showed excellent correlation of all measures of insulin secretion at the different steps of arginine test. We cannot thus exclude that besides increased basal insulin secretion, the increase in maximal secretory capacity would also be seen.

Disposition index calculated from different measurements of $\beta$-cell function from the arginine test and from the insulin sensitivity index as derived from euglycemic clamp did not differ between women with PCOS and control healthy women. The disposition index describes the ability of $\beta$-cells to increase insulin secretion in response to decreased insulin sensitivity. This compensation is finely tuned, and in subjects with normal glucose tolerance, insulin sensitivity and insulin secretion are related to each other in a hyperbolic manner. Our results thus agree with others describing intact compensation in subjects with normal glucose tolerance (Kahn et al. 1993). However, other investigators have found decreased disposition index in women with PCOS in general (Dunaif and Finegood 1996) or with family history of DM 2 (Ehrmann et al. 1995). Finally, Scandinavian authors (Holte et al. 1994) described increased early insulin response and increased disposition index in both lean and obese PCOS. This study was not controlled for family history of DM 2.

Basal glucagon levels were higher in women with PCOS without family history of diabetes than in controls. On the other hand, basal blood glucose was not elevated concomitantly, as one might expect. Glucose inhibition of glucagon secretion was not different in women with PCOS compared to healthy women. These results are in agreement with those of Larsson and Ahren (1996, 2000) who found decreased glucose inhibition of glucagon secretion only in subjects with impaired glucose tolerance. Basal insulin levels tended to be increased in women with PCOS compared to controls. One of the explanations for the increase in both of these glucoregulatory hormones could be the increase in parasympathetic tone on the islets. The increased parasympathetic tone leads to both increased insulin and glucagon secretion (Ahren and Taborsky 1986, Balkan and Dunning 1995).

We conclude that family history of DM 2 is a risk factor for lower insulin sensitivity in PCOS. We observed that only women affected with PCOS with concomitant family history of DM 2 have lower insulin sensitivity than healthy control women. However, they are able to compensate for this decrease in sensitivity with increased insulin secretion.

\section{Conflict of Interest}

There is no conflict of interest.

\section{Acknowledgements}

This study was supported by grant of Czech Ministry of Health NR/ 8759-3. The excellent technical assistance of Mrs. Romana Bajtlová, Jana Novotná and Stanislava Štursová in performing of metabolic examinations is gratefully acknowledged.

\section{References}

AHREN B, LARSSON H: Quantification of insulin secretion in relation to insulin sensitivity in nondiabetic postmenopausal women. Diabetes 51 (Suppl 1): S202-S211, 2002.

AHREN B, TABORSKY GJ, JR.: The mechanism of vagal nerve stimulation of glucagon and insulin secretion in the dog. Endocrinology 118: 1551-1557, 1986.

BALKAN B, DUNNING BE: Muscarinic stimulation maintains in vivo insulin secretion in response to glucose after prolonged hyperglycemia. Am J Physiol 268: R475-R479, 1995.

DEFRONZO RA, TOBIN JD, ANDRES R: Glucose clamp technique: a method for quantifying insulin secretion and resistance. Am J Physiol 237: E214-E223, 1979. 
DUNAIF A: Insulin resistance and the polycystic ovary syndrome: mechanism and implications for pathogenesis. Endocr Rev 18: 774-800, 1997.

DUNAIF A, FINEGOOD DT: B-cell dysfunction independent of obesity and glucose intolerance in the polycystic ovary syndrome. J Clin Endocrinol Metab 81: 942-947, 1996.

DUNAIF A, SEGAL KR, FUTTERWEIT W, DOBRJANSKY A: Profound peripheral insulin resistance, independent of obesity, in polycystic ovary syndrome. Diabetes 38: 1165-1174, 1989.

DUNAIF A, SEGAL KR, SHELLEY DR, GREEN G, DOBRJANSKY A, LICHOLAI T: Evidence for distinctive and intrinsic defects in insulin action in polycystic ovary syndrome. Diabetes 41: 1257-1266, 1992.

EHRMANN DA, STURIS J, BYRNE MM, KARRISON T, ROSENFIELD RL, POLONSKY KS: Insulin secretory defects in polycystic ovary syndrome. Relationship to insulin sensitivity and family history of non-insulindependent diabetes mellitus. $J$ Clin Invest 96: 520-527, 1995.

EHRMANN DA, KASZA K, AZZIZ R, LEGRO RS, GHAZZI MN: Effects of race and family history of type 2 diabetes on metabolic status of women with polycystic ovary syndrome. J Clin Endocrinol Metab 90: 66-71, 2005.

FERRANNINI E: Insulin resistance versus insulin deficiency in non-insulin-dependent diabetes mellitus: problems and prospects. Endocr Rev 19: 477-490, 1998.

HOLTE J, BERGH T, BERNE C, BERGLUND L, LITHELL H: Enhanced early insulin response to glucose in relation to insulin resistance in women with polycystic ovary syndrome and normal glucose tolerance. $J$ Clin Endocrinol Metab 78: 1052-1058, 1994.

HUME R: Prediction of lean body mass from height and weight. J Clin Pathol 19: 389-391, 1966.

KAHN SE, PRIGEON RL, MCCULLOCH DK, BOYKO EJ, BERGMAN RN, SCHWARTZ MW, NEIFING JL, WARD WK, BEARD JC, PALMER JP: Quantification of the relationship between insulin sensitivity and Bcell function in human subjects. Evidence for a hyperbolic function. Diabetes 42: 1663-1672, 1993.

LARSSON H, AHREN B: Islet dysfunction in obese women with impaired glucose tolerance. Metabolism 45: 502-509, 1996.

LARSSON H, AHREN B: Glucose-dependent arginine stimulation test for characterization of islet function: studies on reproducibility and priming effect of arginine. Diabetologia 41: 772-777, 1998.

LARSSON H, AHREN B: Glucose intolerance is predicted by low insulin secretion and high glucagon secretion: outcome of a prospective study in postmenopausal Caucasian women. Diabetologia 43: 194-202, 2000.

LEGRO RS, CASTRACANE VD, KAUFFMAN RP: Detecting insulin resistance in polycystic ovary syndrome: purposes and pitfalls. Obstet Gynecol Surv 59: 141-154, 2004.

MATTHEWS DR, HOSKER JP, RUDENSKI AS, NAYLOR BA, TREACHER DF, TURNER RC: Homeostasis model assessment: insulin resistance and B-cell function from fasting plasma glucose and insulin concentrations in man. Diabetologia 28: 412-419, 1985.

OVESEN P, MOLLER J, INGERSLEV HJ, JORGENSEN JO, MENGEL A, SCHMITZ O, ALBERTI KG, MOLLER $\mathrm{N}$ : Normal basal and insulin-stimulated fuel metabolism in lean women with the polycystic ovary syndrome. J Clin Endocrinol Metab 77: 1636-1640, 1993.

PRATLEY RE, WEYER C: The role of impaired early insulin secretion in the pathogenesis of Type II diabetes mellitus. Diabetologia 44: 929-945, 2001.

TOPRAK S, YONEM A, CAKIR B, GULER S, AZAL O, OZATA M, CORAKCI A: Insulin resistance in nonobese patients with polycystic ovary syndrome. Horm Res 55: 65-70, 2001.

VRBÍKOVÁ J, CIBULA D, DVOŘÁKOVÁ K, STANICKÁ S, ŠINDELKA G, HILL M, FANTA M, VONDRA K, ŠKRHA J: Insulin sensitivity in women with polycystic ovary syndrome. J Clin Endocrinol Metab 89: 29422945, 2004.

WHO: Report of the Expert Committee on the Diagnosis and Classification of Diabetes Mellitus. Diabetes Care 20: 1183-1197, 1997. 